\title{
Números que pouco explicam: indicadores sobre famílias recasadas e bullying
}

\author{
Leila Maria Torraca de Brito ${ }^{a^{*}}$ \\ Laura Cristina Eiras Coelho Soares ${ }^{b}$ \\ a Universidade do Estado do Rio de Janeiro, Departamento de Psicologia Social e Institucional. Rio de Janeiro, RJ, Brasil \\ ${ }^{b}$ Universidade Federal de Minas Gerais, Departamento de Psicologia da Faculdade de Filosofia e Ciências Humanas. \\ Belo Horizonte, MG, Brasil
}

Resumo: No presente artigo, optamos por analisar o recorte metodológico e algumas interpretações, divulgadas pelo Instituto Brasileiro de Geografia e Estatística, provenientes de indicadores obtidos sobre dois temas pesquisados pelo instituto. Nosso objetivo, portanto, foi o de avaliar metodologias e definições empregadas pelo Censo de 2010 na coleta de dados sobre famílias recasadas, bem como a opção metodológica e as acepções utilizadas para a apreensão do bullying na pesquisa PeNSE, de 2009. Como os resultados das investigações empreendidas pelo instituto são usados para traçar o rumo das políticas públicas no Brasil, consideramos ser de suma importância que os procedimentos empregados estejam em consonância com as discussões teóricas atuais sobre os respectivos temas, situação que não foi evidenciada em nossa análise.

Palavras-chave: estatísticas, características da população, bullying, relações familiares, família.

$\mathrm{Na}$ contemporaneidade, estatísticas e índices resultantes de levantamentos e pesquisas realizados sobre os mais diversos temas são mencionados frequentemente. Por vezes, esses dados são apresentados por meio de gráficos e tabelas já analisados, divulgados pela mídia poupando-nos do desafio de decifrar os números obtidos. Não podemos esquecer, entretanto, que para a consecução de tais levantamentos se faz necessário inicialmente delimitar parâmetros para a coleta de dados, executá-la, processar os resultados obtidos e interpretá-los, para então definir como divulgá-los.

Compiègne (2011) analisa que estamos na era da "sociedade numérica", com possibilidades de muitas pessoas, de várias partes do mundo, terem acesso a uma incalculável quantidade de informações, quase ao mesmo tempo, e a uma imensa variedade de dados sobre praticamente todos os assuntos. Como explica a pesquisadora: "depois do homo faber, o homo sapiens ... ., eis agora o advento da era do homo numericus, uma etapa do desenvolvimento da humanidade onde a atividade humana se organiza em torno da tecnologia e de ferramentas numéricas" (Compiègne, 2011, p. 59).

A autora compreende que dessa maneira se opera ampla transformação no contexto social quando, globalmente, as diferentes sociedades encontram-se cada vez mais capturadas pelos progressos da informática e por índices numéricos. Assinala, porém, que não devemos perder de vista que certos avanços tecnológicos estariam em sintonia com projetos políticos que, de alguma forma, visam a mudanças nos modelos culturais e sociais vigentes.

Podemos lembrar, ainda, que a possibilidade recente de livre e rápido acesso ao conhecimento foi inicialmente aplaudida pela comunidade científica na medida em

* Autora correspondente: leila.torraca.brito@gmail.com que, dentre outros fatores, os resultados e as informações de pesquisas poderiam ser facilmente conhecidos e divulgados. Todavia, rapidamente percebemos não ser possível desprezar os desdobramentos do imperativo para o consumo que se instalou na pós-modernidade, quando a quantidade se torna uma variante não só apreciada como valorizada. No âmbito acadêmico universitário, em curto espaço de tempo constatamos que a sonhada possibilidade de amplo acesso e divulgação do conhecimento trouxe, também, inúmeras cobranças para a difusão de produtos surgindo, no contexto nacional, o "Homo lattes", como designou Martins (2013, p. 6). Agora, os pesquisadores se encontram pressionados pela exigência de produtividade constante e abundante, que deve ser divulgada sob a forma de artigos científicos, livros, capítulos de livros, palestras, cursos e uma infinidade de atividades que serão contabilizadas e traduzidas em pontos. Consequentemente, como concluiu o autor, "todo dado qualitativo será redutível a termos quantitativos" (p. 6).

Certamente essa não é apenas uma realidade brasileira. Em Portugal, por exemplo, há a Plataforma DeGóis, muito semelhante àquela que, no Brasil, denominamos de Lattes, em homenagem ao físico César Lattes. Nessas plataformas, cada pesquisador deve manter seu curriculum vitae atualizado, com todos os produtos de seu trabalho detalhados, material que fica disponível na internet e que é usado para classificá-lo como um pesquisador produtivo ou não, "de acordo com uma escala pré-estabelecida de categorias e assim traduzida em pontos" (Martins, 2013, p. 6).

No contexto contemporâneo, portanto, as cifras numéricas assumem um lugar de destaque, sendo que para tudo temos estatísticas e, com frequência, ouvimos que "os números não mentem", como exposto em crônica de Ribeiro (2009). Sem dúvida, não podemos atribuir qualquer 
inverdade aos números, mas talvez seja aconselhável estarmos atentos aos parâmetros que deram embasamento à coleta de dados, às interpretações feitas, bem como às conclusões expostas a partir de percentis divulgados. Acostumados a receber as estatísticas calculadas já relacionadas a certas conclusões, prontamente repetimos as interpretações explicitadas. Assim, temos números que olhamos e resultados que facilmente aceitamos pela falta de tempo para investigar ou avaliar melhor cada assunto. Dessa forma, rapidamente nos apoderamos de mais um produto, sabendo que seu prazo de validade é limitado e que logo teremos acesso a outras investigações com novos números.

No Brasil, estatísticas e pesquisas empreendidas pelo Instituto Brasileiro de Geografia e Estatística (IBGE) são constantemente usadas para embasar a formulação de políticas públicas, bem como é recorrente seu emprego em justificativas de projetos de lei. No início do ano de 2014, entretanto, foram amplamente noticiados equívocos e crises que envolveram instituições de pesquisas nacionais como o IBGE e o Instituto de Pesquisas Econômicas Aplicadas (Ipea). Em abril de 2014, o Ipea reconheceu, publicamente, erros nos índices aferidos em pesquisa de opinião a respeito da tolerância social à violência contra as mulheres. Inicialmente, os resultados da pesquisa apontaram que $65 \%$ dos brasileiros concordariam, total ou parcialmente, com a ideia de que " mulheres que usam roupas que mostram o corpo merecem ser atacadas". O percentual encontrado gerou polêmicas, além de ser manchete de jornais e assunto privilegiado em diversos programas de televisão. Autoridades, celebridades e estudiosos vieram a público lamentar e apresentar explicações a respeito dos números encontrados no Brasil. Entretanto, alguns dias depois o Ipea afirmou que havia erro no resultado anunciado. $\mathrm{O}$ percentual correto seria de $26 \%$, e a "a falha teria sido provocada por uma troca de gráficos" (Weber \& Luiz, 2014, p. 3). O ministro da Secretaria de Assuntos Estratégicos, Marcelo Neri, que à época também era presidente do Ipea, em entrevista divulgada pela imprensa, avaliou que "houve foi uma fatalidade" (Oliveira, 2014, p. 4).

Ainda no início do mês de abril de 2014, foi notícia o pedido de demissão da diretora de pesquisas do IBGE (Spitz, 2014), em virtude da decisão do instituto de suspender a pesquisa nacional por amostra de domicílios contínua (PNAD), que acompanha o mercado de trabalho brasileiro. A interrupção da pesquisa causou uma crise no IBGE, com diversos protestos e funcionários ameaçando deixar os cargos caso a decisão não fosse revista, pois afirmavam que não houve consulta à equipe técnica responsável pela citada pesquisa e que havia ingerência política no IBGE. (Carneiro, De Paula, Jungblut, \& Beck, 2014).

Os impasses gerados nas duas situações podem ser um alerta para que procuremos analisar, de maneira cuidadosa, os resultados de pesquisas que nos são apresentados. Dessa forma, mostra-se relevante verificar, sempre que possível, a metodologia, os pressupostos teóricos que deram embasamento à investigação, além, certamente, das interpretações atribuídas aos dados coletados.
No presente trabalho, optamos por analisar o recorte metodológico e as conclusões provenientes de duas pesquisas recentes realizadas pelo IBGE, divulgadas pela mídia. A primeira refere-se ao Censo Demográfico de 2010 (IBGE, 2010a), sobre a qual decidimos examinar a metodologia empregada para pesquisar a família recasada e a forma escolhida para agrupar os dados obtidos. A segunda investigação avaliada é a PeNSE de 2009 (IBGE, 2009a), mais especificamente quando a mesma aborda o fenômeno do bullying.

\section{Estudos sobre a família recasada: desafios para definição e mapeamento}

No estudo do recasamento, facilmente se evidenciam nomenclaturas distintas usadas para nomear a composição, como: famílias reconstituídas (Grisard Filho, 2003), famílias recompostas (Maldonado, 1986) e famílias recasadas (McGoldrick \& Carter, 1995), dentre outras. Neste artigo, optamos por acompanhar autores que usam a expressão "família recasada" para indicar a formação familiar na qual ao menos um dos cônjuges possui filhos de outro relacionamento.

Quando pensamos em definir a família recasada, diversos autores (Atalaia, 2010; Lobo, 1996; Verón, 2007) alertam para os distintos fatores que devem ser especificados, ou seja, se há exigências de coabitação dos novos cônjuges, de um tempo mínimo de convivência e de oficialização da união. Além disso, é preciso especificar se estamos contabilizando casos de viuvez, de divórcio ou ambos.

No que tange à delimitação de quem integra a família recasada para fins de corte metodológico e planejamento de políticas públicas, torna-se relevante observar também como cada pesquisador circunscreve essa família. Clément e Bonvalet (2006), por exemplo, ao conceituarem "família recomposta" em sua pesquisa, fizeram uma importante ressalva que ficará mais clara ao apresentarmos a seguinte situação: uma mãe separada que não recasou não pertence a uma família recomposta, no entanto, seu filho pode ser integrante de uma organização familiar dessa natureza caso o pai dele tenha casado outra vez. Assim, no mesmo grupo familiar, alguns integrantes comporiam uma família recasada enquanto outros não. A partir dessa distinção outra dúvida pode surgir: um filho nascido em um recasamento pertenceria a uma família recasada, já que seus pais não se separaram? Nessas circunstâncias, ele poderia estar coabitando com um meio-irmão ou com outras crianças que são filhos dos ex-cônjuges de seus genitores, possibilidades existentes em função do recasamento, o que não ocorreria se fosse a primeira união de seus pais. Entendemos que essa delimitação indica a importância de se pensar a partir de quem será contabilizada a família recasada.

Para o Institut National de la Statistique et des Études Économiques (INSEE, 2012a), da França, a questão referente ao modo de determinar os integrantes da família recasada encontra resposta na definição que empregam: "compreende um casal de adultos, casados ou não, e ao menos uma 
criança nascida de uma união precedente de um dos cônjuges. As crianças que vivem com seus pais e seus meio-irmãos também fazem parte de uma família recasada."

Como exposto na citação, esse instituto inclui no conceito os filhos oriundos de um casal que já possuía filhos de uniões pregressas. Além disso, para o INSEE, a criança nascida de um recasamento integraria uma família recasada, mesmo que seus pais não tenham se separado. No entanto, conforme observado por Domingo (2009), essa definição oculta o formato de família no qual somente o genitor não-guardião recasou.

\section{Levantamentos sobre a família recasada}

No Brasil, em 2007 foi divulgado pela mídia (Zakabi, 2007) que para o próximo Censo Nacional os instrumentos de coleta de dados buscariam ampliar as informações sobre as diversidades das famílias brasileiras, inserindo, por exemplo, o mapeamento do número de enteados que residiam em cada casa. De fato, a tarefa foi cumprida no Censo do IBGE de 2010. Para atingir esse objetivo, o Questionário Básico (2010) - que indagava sobre a relação de parentesco ou convivência com a pessoa responsável pelo domicílio - trazia uma questão com a opção de resposta: "enteado". De forma distinta, no questionário anterior, utilizado pelo Censo em 2000, havia apenas uma alternativa que reunia as duas possibilidades: "03 - filho(a), enteado(a)" (IBGE, 2000). Dessa maneira, na resposta não estava previsto qualquer detalhamento a respeito da questão. O uso da expressão "filho(a), enteado(a)" na mesma opção apontava para uma indistinção.

No questionário aplicado em 2010, a inovação reside na criação de três campos detalhados: " 4 - filho(a) do responsável e do cônjuge"; "5 - filho(a) somente do responsável" e "6 - enteado(a)" (IBGE, 2010b, p. 76). Observamos, no entanto, que apesar de haver diferenciação entre filho e enteado, certos resultados apresentados pelo IBGE não aproveitaram esse detalhamento. Equivale a dizer que o modo como as respostas foram analisadas, agregadas em determinadas categorizações, pode ter gerado um sub-registro do número de famílias organizadas a partir de recasamentos. Essa questão pode ser identificada no resultado divulgado pelo IBGE sobre a categoria "mulher sem cônjuge com filho(s)". Sua definição refere-se às organizações familiares "constituídas somente por pessoa responsável pela unidade doméstica do sexo feminino com pelo menos um(a) filho(a) ou enteado(a). Também denominada monoparental feminina com filho(s)" (IBGE, 2010b, p. 38). A categorização "homem sem cônjuge com filho(s)" recebeu o mesmo tratamento (IBGE, 2010b, p. 38).

Notamos, assim, que ao reunir na apresentação dos dados as respostas "filho" com aquelas de "enteado", o mapeamento dessas formações familiares tornou-se difícil, pois a composição familiar formada pelo padrasto/madrasta com o enteado foi interpretada como análoga àquela composta pelo pai/mãe com o filho. Esse dado seria de suma importância para a formulação de políticas públicas.
Nesse caso, reparamos que as informações foram coletadas, mas o modo utilizado para analisá-las não observou as particularidades dos novos arranjos familiares. Ao considerar esses formatos familiares como sinônimos, o IBGE dificulta a reflexão sobre essas estruturas em sua peculiaridade, e a busca por políticas públicas direcionadas a atender essas configurações. Essa análise parece adaptar essas configurações familiares ao mesmo molde, o que promove o silenciamento de suas necessidades e da problematização sobre o exercício dos lugares de padrastos e madrastas.

Sabóia, Cobo e Matos (2012), profissionais que atuam na Gerência de Indicadores Sociais do IBGE, reconhecem que a coleta de dados sobre as diferentes organizações familiares contemporâneas requer instrumentos sofisticados, dada a complexidade das relações familiares atuais. Nesse sentido, relatam que o instituto de pesquisas tem procurado usar ferramentas que possam alcançar tais mudanças. Explicam, também, que: "As Nações Unidas, através da sua Comissão de Estatística e da Comissão Econômica para a Europa (United Nations Economic Commission for Europe - UNECE), vêm buscando subsidiar os sistemas estatísticos nacionais nessa tarefa" (p. 1). Segundo os autores, o IBGE em suas pesquisas tem procurado seguir as recomendações da UNECE.

A partir dos dados reunidos e divulgados pelo IBGE, que constam no documento completo intitulado "Famílias e Domicílio - Resultados da amostra", fornecido posteriormente, foi informado que:

No conjunto do País, 16,3\% das famílias únicas e conviventes principais formadas por casais com filhos podem ser consideradas famílias reconstituídas, ou seja, famílias onde existiam apenas filhos do responsável, apenas filhos do cônjuge ou uma combinação dessas duas situações denominada ... . por outras configurações. (IBGE, 2010a, p. 76)

Dentre os $16,3 \%$ referentes às famílias recasadas, a partir da divisão supracitada, o IBGE chegou aos seguintes dados: 5,8\% sendo somente filhos(as) do responsável; $3,4 \%$ sendo somente filhos(as) do cônjuge; e 7,1\% de outras configurações. No citado documento, essas foram as únicas informações oferecidas pelo Censo 2010 sobre as famílias recasadas. Notamos também que o IBGE, em suas publicações resultantes do Censo, não revelou o número de crianças que residiam com padrastos, com madrastas, quantas famílias recasadas se formaram a partir da viuvez de um dos cônjuges, quantas foram decorrentes de divórcio/separação, como também não apresentou informações detalhadas sobre as fratrias recompostas e a coabitação desses irmãos.

No caso das fratrias, seria importante especificar as "outras configurações", a fim de saber se existem filhos oriundos da união atual que coabitam com os demais ou, ainda, se os 7,1\% referem-se apenas à coabitação entre "irmãos não consanguíneos". Outro aspecto observado foi 
que para configurar uma família recasada, o IBGE partiu do entendimento de que deveria existir a presença de um casal e, portanto, o padrasto com o enteado ou a madrasta com o enteado foram consideradas famílias monoparentais. Seria necessário levantar mais alguns dados por meio do cruzamento de tabelas e análises, todavia ressaltamos que a ausência de maiores esclarecimentos pode sinalizar a pouca visibilidade dada ao fenômeno do recasamento.

Ainda no que se refere à análise da metodologia empregada pelo IBGE no Censo de 2010, observamos que a mensuração das multirresidências - que implica o levantamento da circulação dos filhos por diversas moradias - não foi considerada, pois o IBGE optou por manter o cômputo pela unidade residencial. A escolha a partir de tais parâmetros acarreta no risco de dupla contagem dos filhos, ou de se contabilizar dois lares monoparentais ao invés de uma família recasada. Essa possibilidade foi confirmada pela Coordenadora de Indicadores Sociais do IBGE, dra. Ana Sabóia, em entrevista divulgada na imprensa (Almeida, 2012). Na citada entrevista, a pesquisadora concluiu que, em relação às crianças que circulam por dois lares e casais que residem em moradias distintas, "hoje em dia a gente não tem como mensurar esse fenômeno no Brasil. Estamos caminhando para isso, estamos estudando para que nossas pesquisas possam retratar essa realidade" (Almeida, 2012, p. 27).

O Censo brasileiro de 2010 parece não ter alcançado as particularidades das novas famílias, com consequências no planejamento de políticas públicas. O sociólogo Marcelo Medeiros, da Universidade de Brasília (UnB), cita, por exemplo, em reportagem de Almeida (2012), que a aplicação do Programa Bolsa Família no Brasil parte do entendimento de que a família estaria circunscrita ao domicílio.

A dificuldade de distribuir o auxílio para uma família pós-divórcio repousa exatamente na multirresidência, isto é, como distribuir um benefício em duas casas se o programa social elege um representante da família? Dessa forma, mostra-se relevante o desenvolvimento de investigações que busquem identificar se existem demandas específicas das famílias recasadas que justifiquem a criação de políticas públicas exclusivas para essa formação familiar. Como apontam Sayão e Aquino (2006), na contemporaneidade a família não pode ser definida pela coabitação, já que extrapola a ideia de única residência. Entendimento que nos ajuda a concluir que, ao igualar família ao grupo doméstico, a realidade das configurações familiares atuais não será alcançada.

\section{Famílias recasadas: recortes metodológicos usados na França}

A dificuldade de coleta de dados demográficos referentes à família recasada também foi percebida em outros países. Chardon e Vivas (2009) formularam método de estimativa do número de crianças que viviam em famílias recasadas, na França, no ano de 2006, a partir da combinação de recenseamento e enquetes. Os pesquisadores notaram que a amostra demográfica até então utilizada não permitia identificar a presença de meio-irmão na casa e, portanto, certas famílias recasadas não seriam contabilizadas, fato que motivou a construção de um novo procedimento para o levantamento dos dados. O risco de dupla contagem em função da circulação dos filhos entre a casa da mãe e a do pai também foi aventado pelos investigadores franceses.

Chardon e Vivas (2009) optaram, portanto, pela conjugação das informações coletadas pela enquete Emploi (aplicada no período de 2004 a 2007) com os dados do recenseamento francês de 2006, o que lhes permitiu concluir que, em 2006, na França, cerca de 1,2 milhões de crianças (de 0 a 17 anos) viviam em famílias recasadas. Destas, 420 mil não coabitavam com irmãos da união atual do seu genitor guardião, enquanto outras 740 mil residiam com um irmão que era filho da união vigente. Essa informação veio preencher uma lacuna sobre a magnitude do fenômeno do recasamento e das fratrias recompostas, passando a ser amplamente utilizada nos textos e documentos franceses sobre a família recasada.

Alguns anos depois, ainda no contexto francês, a pesquisa denominada "Des Lieux aux Liens" (Lili), elaborou grande enquete nacional sobre o tema Família e Habitação, aplicada em 2011 pelo Institut National de la Statistique et des Études Économiques (INSEE, 2012b). Naquele ano, a enquete Famille et Logements foi associada ao Censo francês por meio de um questionário de quatro páginas com o qual objetivava-se coletar diversos dados sobre as organizações familiares. No que tange à família recasada, foram incluídos, por exemplo: a faixa etária dos cônjuges e a dos filhos, a existência ou não de fratrias recompostas, o tempo de permanência das crianças naquela residência e os diferentes tipos de filiação. Enfim, buscou-se possibilitar o mapeamento detalhado dessa estrutura familiar.

Um aspecto central que identificamos naquela pesquisa foi o conceito de multirresidência. A pessoa entrevistada informava se ela própria ou algum dos filhos morava em mais de um lar. Em caso positivo, eram solicitados esclarecimentos sobre o tempo que permanecia em cada moradia, e quem residia nos locais. Caso os filhos permanecessem algum tempo na residência do outro responsável, isso era averiguado por meio das seguintes possibilidades de resposta: "todo o tempo", "a metade do tempo ou mais" e "menos da metade do tempo". A fim de complementar os dados, era também questionado se os filhos habitavam regularmente em outra residência. Para essa questão existiam as opções: "não", "sim, na casa do outro genitor", "sim, para seus estudos", "sim, em outro lugar". Outro item referia-se ao detalhamento de informações sobre os filhos que não moravam na mesma casa do respondente.

No que concerne à família recasada, a enquete reunia perguntas sobre as crianças que residiam na casa, questionando se eram filhos do entrevistado e de seu cônjuge, se só do entrevistado, ou se somente do cônjuge. O levantamento também buscou saber se o recasamento era pós-divórcio ou pós-viuvez do entrevistado. O estado 
civil era outro dado contemplado pelo instrumento, que indagava se a pessoa era casada ou possuía união civil ${ }^{1}$. Essas informações, junto aos dados coletados pelo Censo francês, provavelmente permitirão uma melhor compreensão das situações multirresidenciais, bem como das particularidades das denominadas famílias recasadas. Alguns resultados referentes à pesquisa Lili já foram divulgados ${ }^{2}$. Especificamente sobre o tema da família recasada, foi publicado o artigo de autoria de Lapinte (2013) intitulado Uma criança em dez vive em uma família recomposta.

No Brasil, entretanto, a partir do reconhecimento de pesquisadores do IBGE sobre a dificuldade que ainda existe para se apurarem dados que digam respeito às crianças que circulam por dois lares e casais que residem em moradias distintas (Almeida, 2012), questionamos se o que tem sido oferecido em termos sociais, jurídicos e legais acompanhar a necessidade das famílias recasadas. Diante do exposto, observa-se que o mapeamento dessas configurações, que é o suporte para o planejamento de políticas públicas e para a inclusão no tecido social, mostra-se carente de detalhamento no Brasil.

\section{Estudos sobre bullying: discordâncias na definição do fenômeno}

O termo bullying surgiu nos anos 1970 no decorrer de pesquisas realizadas por Dan Olweus, professor da Universidade de Bergen, Noruega. Na página eletrônica do Olweus Bullying Prevention Program há a explicação de que: "bullying é um comportamento agressivo que é intencional e que envolve um desequilíbrio de poder. Frequentemente, isso é repetido ao longo do tempo". Preocupado com as diversas possibilidades de ocorrência do bullying nas escolas, o pesquisador afirma, em sua página, que é preciso saber distinguir as ações que ocasionam o fenômeno. Os trabalhos de Olweus são citados com frequência por estudiosos do tema, como, por exemplo, Fante e Pedra (2008), que explicam que são consideradas repetitivas as ações que ocorreram duas ou mais vezes no curso do ano letivo. Em Fante (2010b), porém, há menção sobre pesquisa realizada pela ONG Plan Brasil, em 2009, na qual se definiu como bullying comportamentos que envolviam maus tratos entre estudantes e que ocorreram três ou mais vezes no ano letivo.

No cenário estrangeiro, o mau-trato entre companheiros de escola também é denominado como "acoso escolar" (Urra, 2007) e "intimidação por colegas" (Smith, 2002). Para este último autor, a intimidação envolveria comportamentos agressivos repetitivos, com "desequilíbrio de poder" entre as partes (p. 187), critérios também listados por outros estudiosos do assunto.

1 A pergunta refere-se ao Pacte civil de solidarité (Pacs), que pode ser equiparado à união estável na legislação brasileira.

2 Outros estudos publicados decorrentes da pesquisa possuem como temática principal os casais e os modos de coabitação e podem ser acessados no site: $\mathrm{http}: /$ www.insee.fr/fr/publics/default.asp?page=communication/ recensement/particuliers/efl1.htm
$\mathrm{Na}$ tentativa de definição do fenômeno, Fante e Pedra (2008) empregam a expressão não só em referência a comportamentos de uma ou mais crianças com outras nas escolas, como às ações entre alunos e professores ou apenas entre os docentes. Reconhecem, ainda, que o fenômeno pode se dar nas organizações familiares, no trabalho, no trânsito e nos condomínios, dentre outros locais. Os citados autores classificam essa conduta como uma "síndrome psicossocial" (p. 35), que deve ser tratada como "questão de saúde pública" (p. 33). Em Fante (2010a), todavia, obtemos a explicação de que comportamentos que envolvem a interação professor-aluno não estariam incluídos no fenômeno, que seria caracterizado pela relação entre pares. Antunes e Zuim (2008), por sua vez, compreendem que o bullying poderia ocorrer entre alunos e professores.

Notamos, portanto, que divergências no que diz respeito à caracterização do bullying não se referem apenas aos grupos envolvidos, mas se estendem aos atos praticados. Assim, enquanto Hilário (2010, p. 32) explica que "não se restringe a atos verbais", Sacco - em entrevista publicada (Paola, 2011, p. 29) - expõe que "o bullying é psicológico e verbal, quando alguém ataca, empurra etc., é crime". Fante e Pedra (2008) incluem na definição de bullying maus-tratos "verbal, físico, moral, sexual, psicológico, material e virtual" (p. 36), listando ações como:

apelidar, ofender, "zoar", "sacanear", humilhar, intimidar, "encarnar", constranger, discriminar, aterrorizar, amendrontar, tiranizar, excluir, isolar, ignorar, perseguir, chantagear, assediar, ameaçar, difamar, insinuar, agredir, bater, chutar, empurrar, derrubar, ferir, esconder, quebrar, furtar e roubar pertences. (p. 36)

Os mesmos autores reconhecem que em distintos países a ocorrência mais significativa seria a de maus tratos verbais, afirmação que também se acha presente na página do Olweus Bullying Prevention Program.

\section{Levantamentos sobre o bullying}

A Pesquisa Nacional de Saúde do Escolar (PeNSE), de 2009, reuniu informações sobre condições de vida de estudantes que se encontravam no $9^{\circ}$ ano do ensino fundamental de escolas públicas, ou privadas, das capitais dos estados brasileiros e do Distrito Federal (IBGE, 2009a). Na citada investigação, conduzida pelo IBGE que contou com parceria do Ministério da Saúde, encontramos a explicação de que a proposta foi de realizar pesquisa com jovens na faixa etária preferencialmente entre 13 e 15 anos de idade para avaliar "fatores de risco e proteção à saúde de adolescentes" (IBGE, 2009b, p. 16). A opção por dar preferência a alunos dessa idade ocorreu não só devido ao fato de possuírem escolaridade suficiente para responder a um questionário autoaplicável, como por ser a idade de referência estabelecida pela Organização Mundial de Saúde. Nas 
notas técnicas, o IBGE esclarece que o questionário a ser respondido foi baseado em instrumentos usados no:

Global School-based Student Health Survey/ Organização Mundial de Saúde - GSHS/OMS, no Youth Risk Behavior Surveillance System/Centers for Disease Control and Prevention - Yrbss/CDC, no Estudo sobre a Condição de Saúde e Nutrição dos Escolares da Cidade do Rio de Janeiro, no Inquérito de Tabagismo em Escolares - Vigescola e nos questionários usados nos seguimentos das coortes de nascimento da Universidade Federal de Pelotas. (p. 6)

Os sujeitos responderam às perguntas em "computador de mão" (IBGE, 2009a, p. 7), o que permitiu maior privacidade, segundo os pesquisadores. Quanto ao questionário formulado, os assuntos privilegiados foram:

características sociodemográficas, alimentação, imagem corporal, atividade física, tabagismo, consumo de álcool e outras drogas, saúde bucal, comportamento sexual, violência, acidentes, segurança, antropometria e apreciação geral do questionário. (IBGE, 2009b, p. 21)

No que diz respeito ao bullying, incluído na temática violência, a pesquisa realizada pelo IBGE concluiu que "quase um terço dos alunos (30,8\%) disseram ter sofrido bullying" (2009a, p. 7). Desse total, 25,4\% sofreram raramente ou às vezes, e 5,4\%, na maior parte das vezes ou sempre. Na investigação, a apuração dos dados a respeito do bullying foi realizada a partir de uma única pergunta: "nos últimos 30 dias, com que frequência algum dos seus colegas de escola te esculachou, zoou, mangou, intimidou ou caçoou tanto que você ficou magoado/incomodado/ aborrecido?" Para a questão existiam cinco opções de resposta: "nenhuma vez"; "raramente"; "às vezes"; "na maior parte das vezes"; "sempre".

Nos resultados divulgados, os pesquisadores explicaram que usaram como definição do termo bullying aqueles comportamentos com graus de violência que incluem

desde chateações inoportunas ou hostis até fatos francamente agressivos, sob forma verbal ou não, intencionais e repetidas, sem motivação aparente, provocado por um ou mais alunos em relação a outros, causando dor, angústia, exclusão, humilhação, discriminação, entre outros. (IBGE, 2009a, p. 9)

Como podemos observar, a pergunta formulada pelo IBGE, exposta anteriormente, soa como indutiva, pois cada aluno deveria responder sobre a frequência de tal acontecimento. Notamos, também, que os jovens não "disseram ter sofrido" (p. 7) bullying, pois, na verdade, essa foi uma interpretação feita por aquele instituto de pesquisas.
Causa-nos estranheza que, apesar de o IBGE definir que os atos vistos como bullying deveriam ocorrer de forma repetida - entendimento, aliás, presente em outros escritos sobre o tema (Fante \& Pedra, 2008; Smith, 2002)-, apenas os alunos que responderam "nenhuma vez nos últimos trinta dias" foram excluídos do grupo denominado de vítimas do bullying. Apesar do uso da expressão "de forma repetida" gerar dúvidas e diferentes interpretações, ensejanos surpresa perceber que todos aqueles que escolheram as opções de resposta "raramente" e "às vezes" foram nomeados como vítimas. O que os estudantes teriam entendido com a expressão raramente? Seria uma vez? Duas ou mais? Em contrapartida, podemos perceber que 5,4\% dos alunos escolheram as opções "na maior parte das vezes" e "sempre".

Observamos também que, apesar de na definição de bullying explicitada pelo IBGE ser feita referência a "chateações inoportunas ou hostis até fatos francamente agressivos, sob forma verbal ou não" (2009a, p. 9), a pergunta escolhida para medir a ocorrência faz menção principalmente a atitudes verbais. Lembramos que, apesar de estudiosos do fenômeno mencionarem que nos países em que vem sendo pesquisada a incidência de maus-tratos verbais, as possibilidades de agressões físicas não são descartadas.

Nesse sentido, entendemos que para melhor compreensão desse fenômeno outros dados deveriam ser levantados na investigação efetuada pelo IBGE em 2009. Seria importante, por exemplo, averiguar se o respondente também já praticou tal comportamento, pois alguns estudos como os de Moura, Cruz e Quevedo (2011), realizado no Rio Grande do Sul, concluíram que quase a metade daqueles identificados como vítimas de bullying já foram protagonistas de atos semelhantes.

Em dezembro de 2010, certa matéria em jornal (Tinoco, 2010) apresentava resultados de investigação realizada no país pela ONG Plan Brasil, ligada a Plan Internacional, organização presente em 60 países, segundo Fante (2010b). Em pesquisa levada a termo no Brasil, também no ano de 2009 , essa ONG concluiu que " $70 \%$ dos alunos informaram ter visto, ao menos uma vez, um colega ser maltratado no ambiente escolar. . . Q Quase $10 \%$ relataram ter sofrido maus-tratos três ou mais vezes no mesmo ano, caracterizando o bullying." (p. 15). Apesar do percentual encontrado pela Plan Brasil ser diferente daquele do IBGE, no relatório referente à primeira investigação (Plan Brasil, 2010) há explicação de que os estudantes - à semelhança do que ocorreu na pesquisa conduzida pelo IBGE não teriam dado respostas específicas sobre bullying, mas como vítimas de maus-tratos, pois na etapa qualitativa da pesquisa se observou que muitos estudantes desconheciam o significado do termo.

Um dos desdobramentos da pesquisa do IBGE foi a Lei estadual 5.824/2010, que prevê a obrigação de escolas do Estado do Rio de Janeiro - tanto públicas quanto particulares - notificarem à autoridade policial e ao Conselho Tutelar da localidade os casos de violência contra crianças e adolescentes, o que inclui as práticas de bullying 
(D’Angelo, 2010). Em decorrência da lei, agora as soluções para tais comportamentos não são buscadas no ambiente escolar, mas em instituições alheias. À escola cabe apenas o diagnóstico do comportamento, o que não é simples. Nesse rumo, propostas para a tipificação penal do bullying surgem em alguns projetos de lei nacionais, sendo incluída no Projeto do Novo Código Penal Brasileiro (PLS 236/2012). Observamos, dessa maneira, que o enfrentamento do problema se desloca para a esfera judiciária.

\section{Discussões sobre a quantificação do fenômeno bullying}

Schilling (2011) descreve que, atualmente, há uma ampliação do que se compreende como práticas violentas, quando rapidamente diversos atos passam a ser incluídos no rol das violências. A autora assinala, no entanto, que mesmo que se classifique um comportamento dessa forma é indicado avaliar quem foi vítima, quem foi o agressor e qual o dano, para que então se defina os procedimentos para evitar tal ocorrência.

No que diz respeito à instituição escolar, Charlot (2005) menciona que é um espaço onde surgem diversos conflitos que não devem ser confundidos com violência. Em rumo semelhante, Body-Gendrot (2002) lamenta a politização em torno do que se nomeia como violência nas escolas e a diversidade de sentidos usados na referência a tal expressão, fato que dificulta o encaminhamento da questão. Argumenta o autor que a denominada segurança nas escolas virou assunto político, dificultando que se pense, com calma, em soluções a serem implantadas. Debarbieux (2010), por sua vez, não crê na eficácia de grandes programas nacionais no combate à violência escolar, motivo pelo qual defende a ideia de que as equipes docentes de cada localidade adaptem tais referências às suas especificidades.

Simon (2011) percebe que, nos estabelecimentos escolares norte-americanos, segurança e tecnologia tornaram-se palavras de ordem. O autor chama atenção para a nítida ampliação do conceito de conduta desviante no contexto escolar daquele país, apontando comportamentos que passaram a integrar essa categoria e estatísticas que incluem fatos até então considerados triviais no ambiente educacional. Em consequência, despontam, nas escolas, práticas derivadas da justiça penal como a instalação de detectores de metais, a contratação de funcionários da área de segurança, interrogatórios, notificações, entre outras. Além disso, a frequente divulgação de estatísticas sobre violência nas escolas gera temor nos pais em relação às instituições de ensino, que deveriam ser vistas como lugares confiáveis para se deixar os filhos. Para esse autor, portanto, o alerta constante sobre os possíveis perigos nas instituições de ensino foi uma opção que resultou em programas de segurança e no uso de diversas tecnologias nas escolas norte-americanas.

Devine (2002) cita que pesquisas por amostragens, que usam questionários aplicados em larga escala, direcionam frequentemente as políticas públicas norte-americanas para prevenção de violência nas escolas com o argumento de que os números traduzem com precisão o que acontece nos estabelecimentos de ensino. Em contraposição, pesquisas qualitativas são realizadas em menor escala. $\mathrm{O}$ autor destaca, ainda, o montante das verbas destinadas a programas de combate e prevenção de violência nas instituições escolares ressaltando, assim como Simon (2011), os produtos de segurança que despontaram naquele mercado.

\section{Considerações finais}

Nossa proposta neste trabalho, certamente, não foi a de desmerecer as pesquisas empreendidas pelo IBGE aqui analisadas, mas a de apontar a importância desses levantamentos e suas respectivas análises serem efetuados a partir do aprofundamento teórico sobre os distintos temas investigados, para que se evitem possíveis equívocos e lacunas nas conclusões das estatísticas divulgadas. $\mathrm{O}$ uso, quando necessário, de instrumentos e indicações estrangeiros para apurar dados quantitativos deve vir acompanhado de estudos específicos sobre o tema para que se possam interpretar devidamente os dados coletados.

Como nos alerta Compiègne (2011), acostumados aos dados numéricos por vezes acabamos por reproduzir facilmente argumentos e conclusões que os índices divulgados apontam, pois, na pós-modernidade, não há tempo para investigarmos ou pensarmos sobre o assunto. Se os percentis nos chegam prontos, com números computados e as conclusões explicitadas, rapidamente nos apoderamos desse produto. Como bem ressaltou Ribeiro (2009), estatísticas sobre diversos temas são constantemente divulgadas, mesmo que revelem cifras díspares. No caso do bullying, mero exemplo pode ser obtido ao compararmos as percentagens encontradas em pesquisa divulgada pela Plan Brasil e pelo IBGE. No entanto, com resultados tão diversos, como pensar em políticas públicas sem saber a dimensão do problema?

Apesar de diversos pesquisadores acentuarem que nem todos os conflitos que surgem no ambiente escolar podem ser nomeados como violência, tal cuidado parece não ter sido tomado pelo IBGE. A avaliação sobre a ocorrência de bullying por meio de uma única pergunta, indutiva, vai de encontro às recomendações feitas por vários estudiosos do tema a respeito da importância de se investigar as especificidades dos atos praticados. Porém, como amplamente noticiado pela mídia, os resultados contribuíram para que rapidamente esse comportamento fosse tratado como assunto político, ensejando novos projetos de lei e legislações específicas, que incluem a tipificação penal do ato perpetrado.

No que diz respeito ao recasamento, como apontamos, este tem sido estudado por meio de diferentes recortes e aproximações metodológicas. Alguns caminhos escolhidos, contudo, revelam inconsistências que culminam em aproximações parciais e, por vezes, equivocadas sobre o tema. $\mathrm{Na}$ comparação entre os instrumentos de coleta de dados sobre famílias recasadas usados na França e no contexto nacional, notamos um refinamento das informações sobre essas famílias naquele país que ainda não existe no 
Brasil. Diante das definições e metodologias eleitas pelo IBGE, entendemos que o Censo brasileiro de 2010 apresentou um avanço no estudo da temática, mas parece não ter alcançado, em sua análise, alguns aspectos específicos dessas novas famílias, acarretando consequências no planejamento de políticas públicas. Pesquisar sobre o tema do recasamento esbarra, portanto, no desafio de construir uma investigação que considere os diversos fatores existentes na constituição desse formato familiar.

Como argumentou Ribeiro (2009), os números não mentem, mas é preciso analisar os parâmetros que sustentaram as coletas de dados, bem como as interpretações feitas a partir dos percentis obtidos. Apesar de não mentirem, os números podem pouco explicar, deixar lacunas ou, ainda, conduzir a interpretações equivocadas.

\section{Agradecimento}

À Coordenação de Aperfeiçoamento de Pessoal de Nível Superior (CAPES), pela Bolsa de Doutorado Sanduíche, Proc. ${ }^{\circ}$ BEX 8742/11-1, concedida no ano de 2012 à segunda autora.

\section{Numbers that does not explain too much: Indicators about remarried families and bullying}

Abstract: In this paper we have chosen to analyze the methodological aspects and some interpretations, divulged by the Brazilian Institute of Geography and Statistics, proceeding from indicators obtained on two topics, surveyed by that institute. Our objective, therefore, was to evaluate methodologies and definitions employed by the 2010 Census in data collection about stepfamilies, as well as the methodological option and meanings used for seizure of bullying in the PeNSE research, 2009. Since the results of the investigations undertaken by the Institute are used to plot the course of public policies in Brazil, we consider the procedures employed should be in line with current theoretical discussions on the respective themes, which has not been evidenced in our analysis.

Keywords: statistics, characteristics of the population, bullying, family relationships, family.

\section{Des chiffres qui expliquent peu: indicateurs sur les familles recomposées et le bullying}

Résumé: Dans cet article, nous avons décidé d'analyser le choix méthodologique et certaines interprétations publiées par I'Instituto Brasileiro de Geografia e Estatística provenant d'indicateurs obtenus par cet institut à propos de deux thèmes. Notre objectif a été diévaluer les méthodologies et les définitions utilisées par le recensement de 2010 lors de la collecte de données sur les familles recomposées, ainsi que le choix méthodologique et les notions utilisées pour la compréhension du bullying dans la recherche PeNSE, 2009. Alors que les résultats des enquêtes menées par l'Institut sont utilisés pour orienter la politique publique au Brésil, nous considérons qu'il est primordial que les procédures utilisées soient en accord avec les discussions théoriques actuelles sur ces thèmes, ce qui n'est pas encore le cas selon notre analyse.

Mots-clés: statistiques, caractéristiques de la population, bullying, relations familiales, famille.

\section{Números que poco explican: indicadores sobre las familias recasadas y bullying}

Resumen: En el artículo en cuestión optamos por analizar el método y algunas interpretaciones, publicados por el Instituto Brasileño de Geografía y Estadística, proveniente de los indicadores obtenidos en dos temas encuestados por el Instituto. Por lo tanto, nuestro objetivo fue evaluar metodologías y definiciones empleadas por lo Censo de 2010 para la recogida de datos de familias reconstituidas, así como la opción metodológica y los significados utilizados para el asimiento del bullying en la encuesta PeNSE, en 2009. Como se utilizan los resultados de las investigaciones realizadas por el Instituto para trazar el curso de las políticas públicas en Brasil, consideramos de suma importancia que los procedimientos empleados están en consonancia con los actuales debates teóricos sobre los respectivos temas, una situación que no se evidenció en nuestro análisis.

Palabras-clave: estadísticas, características de la población, acoso escolar, relaciones familiares, família. 


\section{Referências}

Almeida, C. (2012, 29 de agosto). Em duas casas, a vida com pai e mãe: IBGE ainda não conta novas famílias, como as que têm guarda compartilhada. O Globo, pp. 27.

Antunes, D. C., \& Zuin, A. A. S. (2008). Do bullying ao preconceito: os desafios da barbárie à educação. Psicologia \& Sociedade, 20(1), 33-42. doi: 10.1590/ S0102-71822008000100004

Atalaia, S. (2010). O lugar do padrasto no quotidiano familiar. In K. Wall, S. Aboim, \& V. Cunha (Orgs.), A Vida Familiar no Masculino: Negociando Velhas e Novas Masculinidades (pp. 397- 455). Lisboa: Editora Comissão para a Igualdade no Trabalho e no Emprego

Body-Gendrot, S. (2002). Violência escolar: um olhar comparativo sobre políticas de governança. In E. Debarbieux \& C. Blaya (Orgs.), Violência nas escolas e políticas públicas (pp. 165-186). Brasília, DF: Unesco.

Brasil. Projeto de Novo Código Penal Brasileiro (PLS 236/2012). Recuperado de www.senado.gov.br/ atividade/materia/detalhes.asp?p cod mate $=106404$

Carneiro, L., De Paula N., Jungblut, C., \& Beck, M. (2014, 12 de abril). Ameaça de debandada no IBGE. O Globo, pp. 33-34.

Chardon, O., \& Vivas, E. (2009). Les familles recomposées: entre familles traditionnelles et familles monoparentales. Institut National de la Statistique et des Études Économiques: INSEE:France. Série de Documents de Travail de la Direction des Statistiques Demographiques et Sociales, F0904.

Charlot, B. (2005). A violência na escola: o que a escola pode fazer e como? In Anais Congresso Ibero-americano sobre violências nas escolas, II Congresso Ibero-americano sobre violências nas escolas (p. 1-27). Belém, PA: Universidade da Amazônia.

Clément, C., \& Bonvalet, C. (2006). Les espaces de vie des familles recomposées. (Collection Recherches 161). Paris: PUCA.

Compiègne, I. (2011). La société numérique en question(s). Paris: Sciences Humaines Éditions.

D’Angelo, R. (2010, 24 de setembro). Bullying: notificação será obrigatória. $O$ Globo, pp. 23.

Debarbieux, É. (2010). Pedagogie contre violence. Entretien avec Eric Debarbieux. Revue Sciences Humaines, 5. Recuperado de http://www.scienceshumaines. com/pedagogie-contre-violence-entretien-avec-ericdebarbieux_fr_14902.html.

Devine, J. (2002). A mercantilização da violência escolar. In E. Debarbieux \& C. Blaya, (Orgs.), Violência nas escolas e políticas públicas (pp. 207-222). Brasília, DF: Unesco.

Domingo, P. (2009). Le quotidien des familles recomposées. Revue Politiques sociales et familiale 96 (jun),96-104.

Estado do Rio de Janeiro (2010). Lei estadual 5.824 de 20 de setembro de 2010. Altera o artigo $1^{\circ}$ da lei $\mathrm{n}^{\mathrm{o}} 4725$, de 15 de março de 2006, e dá outras providências. Rio de Janeiro, RJ: Governo do Estado.
Fante, C. (2010a, $1^{\circ}$ de agosto). Bullying no ambiente escolar. Revista Jurídica Consulex, 325, 36-38.

Fante, C. (2010b). Programa de Enfrentamento ao Bullying no ambiente escolar. Campanha Aprender sem medo. São Luis, MA: Plan Brasil. Recuperado de http://www.plan. org.br/publicacoes/download/cartilha_enfrentamento bullying.pdf

Fante, C., \& Pedra, J. A. (2008). Bullying escolar: perguntas \& respostas. Porto Alegre, RS: Artmed.

Grisard Filho, W. (2003). Famílias reconstituídas: breve introdução ao seu estudo. In G. Groeninga \& R. C. Pereira (Orgs.), Direito de família e psicanálise: rumo a uma nova epistemologia (pp. 255-268). Rio de Janeiro: Imago.

Hilário, L. A. R. (2010, $1^{\text {o }}$ de agosto). Bullying: um novo desafio? Revista Jurídica Consulex, 325, 32-33.

Instituto Brasileiro de Geografia e Estatística (IBGE, 2000). Questionário Básico IBGE 2000. Recuperado de http:// www.ibge.gov.br/censo/quest_basico.pdf

Instituto Brasileiro de Geografia e Estatística (IBGE, 2009a). Pesquisa Nacional da Saúde do Escolar (PeNSE). Rio de Janeiro: IBGE. Recuperado de http://www.ibge.gov.br/ home/presidencia/noticias/noticia_impressão.php?id noticia $=1525$

Instituto Brasileiro de Geografia e Estatística (IBGE, 2009b). Pesquisa Nacional da Saúde do Escolar (PeNSE) 2009. Rio de Janeiro: IBGE. Recuperado de

http://www.ibge.gov.br/home/estatistica/populacao/pense/ pense.pdf

Instituto Brasileiro de Geografia e Estatística (IBGE, 2010a). Censo Demográfico 2010 - Famílias e domicílios Resultados da amostra. Recuperado de ftp://ftp.ibge. gov.br/Censos/Censo_Demografico_2010/Familias_e_ Domicilios/censo_fam_dom.pdf

Instituto Brasileiro de Geografia e Estatística (IBGE, 2010b). Questionário Básico IBGE 2010. Recuperado de: http://censo2010.ibge.gov.br/images/pdf/censo2010/ questionarios/questionario_basico_cd2010.pdf

Institut National de la Statistique et des Études Économiques (INSEE, 2012a). Definition Famille Recomposée. Recuperado de http://www.insee.fr/fr/methodes/default. asp? page $=$ definitions $/$ famille-recomposee.htm

Institut National de la Statistique et des Études Économiques (INSEE, 2012b). Questionnaire enquete Famille et Logement. Recuperado de: http://www.insee.fr/fr/ publics/collectivites/questionnaire-homme-enquetefamille-logement.pdf

Lapinte, A (2013). Un enfant sur dix vit dans une famille recomposée. Insee Première, 1470. Recuperado de: http://www.insee.fr/fr/themes/document.asp?reg_ $\mathrm{id}=0$ \&ref_id $=\mathrm{ip} 1470$

Lobo, C. (1996). Padrastos no quotidiano: estratégias de construção social do papel de padrasto. Sociologia, problemas e práticas, 9, 67-82.

Maldonado, M. T. (1986). Casamento: término e reconstrução. Petrópolis, RJ: Vozes. 
Martins, S. B. (2013, 3 ago.). Homo Lattes. O Globo, p. 6.

McGoldrick, M., \& Carter, B. (1995). Constituindo uma família recasada. In M. McGoldrick \& B. Carter (Orgs.), As mudanças do ciclo de vida familiar: uma estrutura para a terapia familiar (pp. 344-369). Porto Alegre, RS: Artes Médicas.

Moura, D. R., Cruz, A. C. N., \& Quevedo, L. A (2011). Prevalência e características de escolares vítimas de bullying. Jornal de Pediatria, 87 (1), 9-23.

Oliveira, F. (2014, 7 de abril). Entrevista: Marcelo Neri. 'Há pessoas tentando jogar a instituição no lixo'. O Globo, pp. 4.

Olweus Bullying Prevention Program. Recuperado de http:// www.violencepreventionworks.org/public/index.page

Paola, F. (2011). Anjos vingadores: Bullying é show e um ato psicológico repetido na frente de uma plateia, afirma um dos maiores especialistas do tema nos EUA. Revista Cult, 157, 28-30.

Plan Brasil (2010). Pesquisa: Bullying escolar no Brasil. Relatório final. Recuperado de

http://www.promenino.org.br/portals/0/pesquisabullying.pdf Ribeiro, J. U. (2009, 9 de agosto). Os números não mentem. O Globo, pp. 7.

Sabóia, A. L., Cobo, B., \& Matos, G. G. (2012). Desafios e possibilidades da investigação sobre os novos arranjos familiares e a metodologia para identificação de família no Censo 2010. In Anais do Encontro Nacional de Estudos Populacionais, XVIII Encontro Nacional de Estudos Populacionais. Águas de Lindóia: Associação Brasileira de Estudos Populacionais. Recuperado de http://www.abep.nepo.unicamp.br/xviii/anais/files/ ST40\%5B161\%5DABEP2012.pdf.

Sayão, R., \& Aquino, J. G (2006). Família: modos de usar. São Paulo, Campinas: Papirus.
Schilling, F. (2011). Direitos Humanos, violência e o desafio do atendimento a vítimas: a busca por justiça. In K. M. Dott, P. C. Endo, S. E. Sposito \& T. C. Endo (Orgs.), Psicologia, violência e direitos humanos (pp. 56-68). São Paulo, SP: Conselho Regional de Psicologia de São Paulo.

Simon, J. (2011). Gobernar a través del delito. Barcelona: Gedisa Editorial.

Smith, P. K. (2002). Intimidação por colegas e maneiras de evitá-la. In E. Debarbieux, \& C. Blaya. Violência nas escolas e políticas públicas (pp. 187-206). Brasília, DF: Unesco.

Spitz, C. (2014, 11 de abril). Diretora do IBGE sai após pesquisa parar. $O$ Globo, pp. 27.

Tinoco, D. (2010, 12 de dezembro). "Bullying" atinge milhares de estudantes no país. O Globo, pp. 15.

Urra, J. (2007). El pequeño dictador. Madrid: La esfera de los livros.

Véron, B. (2007). Héritages symboliques et rapports aux lignés dans les familles recomposées. Revue Recherches familiales, 4, 25-33.

Weber, D., \& Luiz W. (2014, 5 de abril). Ipea admite erro em pesquisa. $O$ Globo, pp. 3.

Zakabi, R. (2007, 23 de maio). Com o seu advogado ou com o meu? - a justiça busca como lidar com os conflitos que surgem na nova família brasileira, com seus hábitos e costumes que ainda não estão previstos nas leis. Revista Veja, 2009, 116-120. 